
THURSDAY, 15 JUNE TO SATURDAY, 17 JUNE 2017
Building patient led organisations

\section{PARE0020 25 YEARS OF PATIENTS' ASSOCIATIONS OF ANKYLOSING SPONDYLITIS IN SPAIN: ACEADE}

J.L. Garrido-Castro ${ }^{1}$, C. Gonzalez-Navas ${ }^{2}$, J. De La Haza ${ }^{1}$, P. Plazuelo ${ }^{3}$, E. Collantes-Estevez ${ }^{4}$. ${ }^{4}$ ACEADE. AS Patient Association of Cordoba; ${ }^{2}$ CEADE. National Coordinator of AS Patient Associations, Cordoba: ${ }^{3}$ CEADE. National Coordinator of AS Patient Associations, Madrid; ${ }^{4}$ Reina Sofia University Hospital, Cordoba, Spain

Background: Patients' associations can provide to the ankylosing spondylitis (AS) patient all the information and support that his/her rheumatologist cannot give and that is necessary to fight against the disease having a greater quality of life (1). Patients' and families' knowledge about AS is fundamental and Patients' associations play an important role in education on disease (2). In 1991, the first association dedicated to AS in Spain, was born: ACEADE (Asociacion Cordobesa de Enfermos Afectados de Espondilitis). The Rheumatologist, Dr Eduardo Collantes, after having spent some years in several countries, brings together several patients affected by this disease, in the city of Cordoba, to create the first Patients Association dedicated to this disease in Spain. There were some associations of this kind in the UK and France, and they decided to create their own association to promote the knowledge about AS and to help the AS patients. 25 years later, there are many AS patient associations in Spain that were created following the example of ACEADE, and with the help of this pioneering association.

Objectives: The aims of ACEADE during these 25 years has been:

1) Disseminate the knowledge of the disease.

2) Collaborate with medical researchers.

3) Improve the quality of life of the AS patient.

4) Organize and participate in scientific meetings, congresses and specialized courses.

5) Advise the patients in socio-labor aspects.

6) Inform associates of the advances related to the disease.

Methods: Several activities are being carried out in the Association, some of them were exposed previously (3): educational seminars, rehabilitation courses, patient guides, social events, legal advice, employment bureau, newsletter, web page, ... In order to develop these activities, we have several sources for fundraising: donations, local and regional governments, pharmaceuticals, foundations, ...

Results: ACEADE is formed by 415 members distributed in the province of Cordoba (Spain), although some of them are from outside this city (11\%). $67 \%$ of them are men and the average age of the members is 53 years. Of these, $32 \%$ have a recognized legal disability. After ACEADE, up to 18 patient associations have been created in Spain. There is also a national organization of AS patient associations: CEADE.

Conclusions: ACEADE was the pioneering AS Association in Spain and has been the "mother" of others that have been appearing. Today there are associations of AS in virtually all territories of Spain, helping patients to have a better quality of life. The next 25 years appear, for our association, full of illusions, ideas and a lot of work ahead, to help in the fight against AS.

References:

[1] J.L. Garrido-Castro, E. Collantes, J. Blancat, J. Roman. Fighting against spondylitis from inside: what could do a patients' association. Ann Rheum Dis 2008:67(Suppl II):683

[2] J. L. Garrido-Castro, E. Collantes-Estevez, C. Gonzalez-Navas, L. Carmona. What is the knowledge level that ankylosing spondylitis patients have about their own disease? Ann Rheum Dis 2013;72(Suppl3):141.

[3] J.L. Garrido-Castro, B. Martos, E. Collantes, J. Blancat. Rheumatic patients' associations in spain: organization, fundraising, activities and relationship with health professionals. Ann Rheum Dis 2010;69(Suppl3):754.

Disclosure of Interest: None declared

DOI: 10.1136/annrheumdis-2017-eular.4754

\section{PARE0021 PUBLIC AND PATIENT INVOLVEMENT AT ARTHRITIS RESEARCH UK: ENSURING BENEFIT FOR ALL}

\section{Macdonald. Arthritis Research UK, London, United Kingdom}

Background: Since 2008, Arthritis Research UK have utilised the valuable experience and perspective of people with arthritis to review and evaluate the research applications we receive, through the USER stakeholder committee. The world of public and patient involvement (PPI) has developed and progressed hugely in that time. So too has Arthritis Research UK, becoming an insight-led charity that can now genuinely say that people with arthritis are at the centre of everything we do, helping those people to be in control, independent and recognised. As such, our approach to PPI must not only meet the new high standards of meaningful PPI set by the research community but also serve to anchor our research activities and the work that we fund in genuine relevance and patient benefit.

Objectives: To present our new approach to involving people with arthritis in the decision-making processes of research and the wider charity.
Methods: We carried out a UK-wide scoping exercise, consisting of questionnaires and one-to-one interviews, of key stakeholder groups and PPI leaders. This included: our funded researchers and centres of excellence; medical research charities; and people with arthritis including ex- and current USER members. The findings were written up in to a report.

Results: The findings of the report highlighted to us that we need to 1) scale up our PPI activities in order to ensure that insight of people with arthritis can be integrated at all stages of the research cycle 2) improve the quality of our PPI ensuring that all the things we do are carried out with clear purpose, that they are meaningful and add mutual value to all involved 3 ) increase the numbers of people with arthritis in our PPI group to help realise this vision, whilst improving our support, training and guidance processes for those people 4) recognise and support the already excellent PPI activities going on in the musculoskeletal community, and providing resources and training for those also wishing to start or improve PPI activities.

Conclusions: After implementing this new approach for over a 18 months, we are now confident that our research activities and the research we fund, have the utmost relevance and potential benefit to people with arthritis.

Disclosure of Interest: None declared

DOI: 10.1136/annrheumdis-2017-eular.2475

\section{PARE0022 ORGANIZATION OF GROUP EXERCISE THERAPY (GET) FOR PATIENTS WITH AXIAL SPONDYLOARTRITIS (AXSPA) IN THE NETHERLANDS; A NATIONWIDE SURVEY}

F. Van Der Giesen ${ }^{1,2}$, S. Van Weelij ${ }^{1}$, N. Lopuhaa ${ }^{3}$, T. Vliet Vlieland ${ }^{1}$. ${ }^{1}$ Orthopedics, Leiden University Medical Center, Leiden; ${ }^{2}$ Rheumatology, Haga Teaching Hospital, The Hague ${ }^{3}$ Dutch Arthritis Foundation, Amsterdam, Netherlands

Background: Exercise therapy is recommended for people with axSpA [1]. In the Netherlands GET specifically for patients with axSpA is usually organized by local rheumatology patient organizations. New scientific insights into the delivery of GET have emerged over the past years and structural reimbursement from the basic health insurance was terminated. To ensure the quality and continuity of the delivery of GET it is necessary first to determine their current structure and processes.

Objectives: To describe the structure and processes of group exercise therapy specifically for patients with axSpA in the Netherlands.

Methods: Using the database of the Dutch Arthritis Foundation in 2016 a pen-and-paper questionnaire was sent to the coordinators of all 82 local patient organizations who could potentially be involved in the delivery of AxSpA GET. The questionnaire comprised 18 questions on the numbers of groups and participating patients, organizational and financial responsibilities, recruitment methods for participants and supervisors, the type of exercise therapy provided (land based, hydrotherapy or a combination of both) and the perceived threats for future continuation.

Results: The questionnaire was returned by 66 of the 82 coordinators of whom17 stated their organization was involved in the delivery of axSpA specific GET (45 group therapy classes: 1 only land exercises; 13 only hydrotherapy; 31 combination) for 496 patients (estimated number of patients with axSpA in the Netherlands in 2016: 61.200 [2]). 15/17 local patient organisations have organisational as well as financial responsibilities. The most often used recruitment methods for participants were: via the rheumatologist/rheumatology nurses $(n=17)$, physical therapists $(n=8)$, or advertisement in local patient organisations' own media $(n=8)$. Recruitment of supervisors was most often done by asking around within their own network $(n=14)$ or asking the leaving supervisor for replacement $(n=8)$. Regular evaluation of the delivery of care with the supervisors and participants was performed by 10 and 12 local patient organizations, respectively. Three had an agreement with health insurance companies regarding reimbursement of GET. In 6 regions the number of participants had been declining over the past 5 years. The most mentioned threats for continuity by coordinators were financial difficulties $(n=7)$ and recruiting participants $(n=9)$.

Conclusions: 17 local rheumatology patient organizations involved in the delivery of GET specifically for patients with axSpA in the Netherlands were identified. The large majority played an active role in the organization and reimbursement and regular evaluation of care delivery was done by two-thirds of them. Future challenges are the recruitment of new participants and reimbursement. As only a small minority of AxSpA patients appears to take part in group exercise therapy, more insight into the needs and preferences among the larger population is needed.

References:

[1] Van der Heijde D, Ramiro S, et al. 2016 update of the ASAS-EULAR management recommendations for axial spondyloarthritis. Ann Rheum Dis 2017 Jan 13.

[2] Stolwijk C, van Onna M, et al. Global Prevalence of Spondyloarthritis: A Systematic Review and Meta-Regression Analysis. Arthritis care \& research. 2016;6:1320-31

Acknowledgements: This study was funded by the Dutch Arthritis Foundation. Disclosure of Interest: None declared

DOI: 10.1136/annrheumdis-2017-eular.4197 